\title{
Design, development, and performance of X-ray mirror coatings for the ATHENA mission
}

Della Monica Ferreira, Desiree; Massahi, Sonny; Christensen, Finn Erland; Shortt, Brian; Bavdaz, Marcos; Collon, Maximilien J.; Landgraf, Boris; Gellert, Nis Christian; Korman, Jakob; Dalampiras, Paschalis

Total number of authors:

14

Published in:

Proceedings of SPIE 10399

Link to article, DOI:

10.1117/12.2273603

Publication date:

2017

Document Version

Publisher's PDF, also known as Version of record

Link back to DTU Orbit

Citation (APA):

Della Monica Ferreira, D., Massahi, S., Christensen, F. E., Shortt, B., Bavdaz, M., Collon, M. J., Landgraf, B.,

Gellert, N. C., Korman, J., Dalampiras, P., Rasmussen, I. F., Kamenidis, I., Krumrey, M., \& Schreiber, S. (2017). Design, development, and performance of X-ray mirror coatings for the ATHENA mission. In S. L. O'Dell, \& G. Pareschi (Eds.), Proceedings of SPIE 10399: Optics for EUV, X-Ray, and Gamma-Ray Astronomy VIII (Vol. 10399). [1039918] SPIE - International Society for Optical Engineering. https://doi.org/10.1117/12.2273603

\section{General rights}

Copyright and moral rights for the publications made accessible in the public portal are retained by the authors and/or other copyright owners and it is a condition of accessing publications that users recognise and abide by the legal requirements associated with these rights.

- Users may download and print one copy of any publication from the public portal for the purpose of private study or research.

- You may not further distribute the material or use it for any profit-making activity or commercial gain

- You may freely distribute the URL identifying the publication in the public portal 


\section{Design, development, and performance of $x$-ray mirror coatings for the ATHENA mission}

Desiree Della Monica Ferreira, Sonny Massahi, Finn E. Christensen, Brian Shortt, Marcos Bavdaz, et al.

Desiree Della Monica Ferreira, Sonny Massahi, Finn E. Christensen, Brian Shortt, Marcos Bavdaz, Maximilien J. Collon, Boris Landgraf, Nis C. Gellert, Jakob Korman, Paschalis Dalampiras, Ida F. Rasmussen, Ifikratis Kamenidis, Michael Krumrey, Swenja Schreiber, "Design, development, and performance of $x$-ray mirror coatings for the ATHENA mission," Proc. SPIE 10399, Optics for EUV, X-Ray, and Gamma-Ray Astronomy VIII, 1039918 (29 August 2017); doi: 10.1117/12.2273603

SPIE Event: SPIE Optical Engineering + Applications, 2017, San Diego, California, United States 


\title{
Design, development, and performance of X-ray mirror coatings for the ATHENA mission
}

\author{
Desiree Della Monica Ferreira ${ }^{a}$, Sonny Massahi ${ }^{a}$, Finn E. Christensen ${ }^{a}$, Brian Shortt $^{b}$, Marcos $^{a}$ \\ Bavdaz $^{b}$, Maximilien J. Collon ${ }^{c}$; Boris Landgraf ${ }^{c}$, Nis C. Gellert ${ }^{a}$, Jakob Korman ${ }^{a}$, \\ Paschalis Dalampiras $^{a}$, Ida F. Rasmussen ${ }^{a}$, Ifikratis Kamenidis ${ }^{a}$, Michael Krumrey ${ }^{d}$, Swenja \\ Schreiber ${ }^{d}$

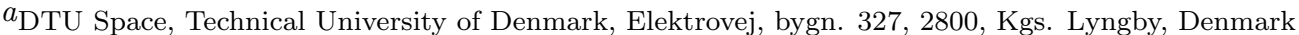

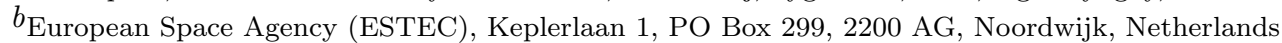

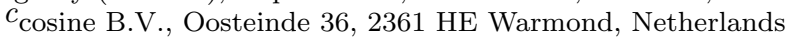 \\ $d_{\text {Physikalisch-Technische Bundesanstalt (PTB), Abbestraße 2-12, } 10587 \text { Berlin, Germany }}$
}

\begin{abstract}
We report the latest results on coating design optimisation and optics performance for the present $\mathrm{Ir} / \mathrm{B}_{4} \mathrm{C}$ baseline coating and alternative designs and materials, including bilayers and linear graded multilayers. We make use of $\mathrm{X}$-ray reflectometry (XRR) to test both coating performance and robustness.
\end{abstract}

Keywords: ATHENA, SPO, coating design, X-ray mirrors, XRR, multilayer, X-ray optics, $\mathrm{Ir} / \mathrm{B}_{4} \mathrm{C}$

\section{INTRODUCTION}

The ATHENA (Advanced Telescope for High Energy Astrophysics) ${ }^{1}$ is a European X-ray mission with planned launch in 2028. Over the past years we have reported the advancements on coating design and development focussing on maximising the performance of the telescope. ${ }^{2-8}$

Since we last reported coating designs ${ }^{5}$ a new geometry for the optics of the Advanced Telescope for High Energy Astrophysics (ATHENA) mission, ${ }^{9}$ has been adopted ${ }^{10},{ }^{11}$ therefore we include in this paper an updated baseline coating review and a review of the optical setup considered for coating design optimisation and simulation of performance.

The present coating baseline for ATHENA is a single bilayer made of $\mathrm{Ir}$ and $\mathrm{B}_{4} \mathrm{C}$. The same coating recipe is considered for all X-ray mirror plates. The goal of this study is to re-optimise the coating design based on the new geometry and further investigate whether the use of multilayers of a heavy (absorber) reflecting layer combined with a light (spacer) material underneath the baseline bilayer coating would be able to improve reflection beyond $5 \mathrm{keV}$ without compromising the performance at lower energies.

The concept adopted in this study is of a single X-ray telescope with a fixed focal length of $12 \mathrm{~m}$, the energy range between 0.1 and $10 \mathrm{keV}$. With a innermost radius of $0.25 \mathrm{~m}$ and outermost radius of $1.5 \mathrm{~m}$, the grazing incidence angle range for ATHENA is from $5.376 \mathrm{mrad}$ to $31.102 \mathrm{mrad}$ distributed over 20 rows of mirror modules. ${ }^{11}$

The requirement for ATHENA's on-axis effective area is $2 \mathrm{~m}^{2}$ at $1 \mathrm{keV}$ (with a goal of $2.5 \mathrm{~m}^{2}$ ), at $6 \mathrm{keV}$ the requirement for the on-axis effective area is $0.25 \mathrm{~m}^{2}$ (with goal of $0.3 \mathrm{~m}^{2}$ ). ${ }^{12}$

Further author information:

Send correspondence to:

Desiree Della Monica Ferreira, e-mail: desiree@space.dtu.dk

Optics for EUV, X-Ray, and Gamma-Ray Astronomy VIII, edited by Stephen L. O'Dell, Giovanni Pareschi, Proc. of SPIE Vol. 10399, $1039918 \cdot$ @ 2017 SPIE · CCC code: 0277-786X/17/\$18 · doi: 10.1117/12.2273603 


\begin{tabular}{cccc}
\hline \hline Ring & Width $(\mathrm{mm})$ & Length $(\mathrm{mm})$ & Mid Radius $(\mathrm{m})$ \\
\hline 1 & 37.096 & 101.504 & 0.286 \\
2 & 50.158 & 83.388 & 0.348 \\
3 & 49.838 & 70.762 & 0.411 \\
4 & 49.613 & 61.460 & 0.473 \\
5 & 89.363 & 54.321 & 0.535 \\
6 & 82.476 & 48.671 & 0.597 \\
7 & 77.571 & 44.087 & 0.659 \\
8 & 86.892 & 40.294 & 0.722 \\
9 & 82.053 & 37.104 & 0.784 \\
10 & 90.205 & 34.383 & 0.846 \\
11 & 85.538 & 32.036 & 0.908 \\
12 & 92.782 & 29.990 & 0.970 \\
13 & 88.326 & 28.191 & 1.032 \\
14 & 94.845 & 26.597 & 1.095 \\
15 & 90.608 & 25.175 & 1.157 \\
16 & 87.079 & 23.898 & 1.219 \\
17 & 92.510 & 22.746 & 1.281 \\
18 & 89.107 & 21.700 & 1.344 \\
19 & 94.119 & 20.748 & 1.406 \\
20 & 90.845 & 19.876 & 1.468 \\
\hline \hline
\end{tabular}

Table 1. ATHENA SPO information for each mirror module ring. ${ }^{11}$

\section{ATHENA'S PRESENT GEOMETRY AND DESIGN}

The X-ray optics of ATHENA is based on Silicon Pore Optics (SPO) mirror modules ${ }^{13,14}$ For the computations presented here, we assume that all mirror modules have same height $(\approx 54 \mathrm{~mm})$, with mirror plate width and length varying according to the radial position (see table 1).

To compute the grazing incidence angles for each radii, we assume a conical approximation of a Wolter-I design,

$$
\tan 4 \alpha=\frac{r}{F_{L}},
$$

where $\mathrm{F}_{L}$ is the focal length $(12 \mathrm{~m})$ and $\mathrm{r}$ the mirror radius. The grazing incidence angles $(\alpha)$ for the mid radius of each ring are listed in table 2 .

The telescope effective area $\left(A_{e f f}\right)$ as a function of photon energy $(E)$ depends on the coating used for the reflecting surfaces within the pores. The maximum energy which can be reflected by a module is determined by the grazing incidence angles $(\alpha)$ and hence the radius of the module in the aperture $(R)$. Each ray suffers two reflections so the collecting area depends on the square of the reflectivity $(R)$. The on-axis effective area $A_{e f f}$ is therefore defined as

$$
A_{\text {eff }}=\sum_{i=1}^{n_{p}} A_{p} \cdot R(E, \alpha)^{2} .
$$

In equation $2, A_{p}\left(P_{L}, \alpha\right)$ is the projected pore area, $R(E, \alpha)$ is the mirror reflectance, and $n_{p}$ is the total number of pores for all reflecting mirror plates.

Table 2 lists grazing incidence angle, number of mirror modules, projected area, reflectivity at $1 \mathrm{keV}$ and effective area at $1 \mathrm{keV}$ for each of the optics ring. The mirror reflectivity is computed assuming the coating baseline (Ir/ $\mathrm{B}_{4} \mathrm{C}$ bilayer) and using the IDL software package IMD. ${ }^{15}$ 


\begin{tabular}{cccccc}
\hline \hline ring & $\begin{array}{c}\text { grazing } \\
\text { angle }\left(^{\circ}\right)\end{array}$ & $\begin{array}{c}\text { number } \\
\text { of MMs }\end{array}$ & $\begin{array}{c}\text { projected } \\
\text { area }\left(\mathrm{m}^{2}\right)\end{array}$ & $\begin{array}{c}\text { reflectivity } \\
\text { at } 1 \mathrm{keV}\end{array}$ & $\begin{array}{c}\text { on-axis } \mathrm{A}_{\text {eff }} \\
\text { at } 1 \mathrm{keV}\left(\mathrm{cm}^{2}\right)\end{array}$ \\
\hline 1 & 0.341 & 30 & 0.038 & 0.973 & 0.0357 \\
2 & 0.416 & 30 & 0.051 & 0.965 & 0.0477 \\
3 & 0.490 & 36 & 0.060 & 0.959 & 0.0553 \\
4 & 0.564 & 42 & 0.070 & 0.952 & 0.0637 \\
5 & 0.638 & 30 & 0.091 & 0.945 & 0.0815 \\
6 & 0.713 & 36 & 0.101 & 0.939 & 0.0888 \\
7 & 0.787 & 42 & 0.110 & 0.931 & 0.0958 \\
8 & 0.861 & 42 & 0.123 & 0.924 & 0.1053 \\
9 & 0.935 & 48 & 0.134 & 0.916 & 0.1128 \\
10 & 1.010 & 48 & 0.147 & 0.908 & 0.1216 \\
11 & 1.084 & 54 & 0.157 & 0.899 & 0.1268 \\
12 & 1.158 & 54 & 0.170 & 0.890 & 0.1346 \\
13 & 1.232 & 60 & 0.180 & 0.881 & 0.1401 \\
14 & 1.307 & 60 & 0.193 & 0.871 & 0.1463 \\
15 & 1.381 & 66 & 0.203 & 0.861 & 0.1504 \\
16 & 1.455 & 72 & 0.214 & 0.850 & 0.1545 \\
17 & 1.529 & 72 & 0.226 & 0.838 & 0.1588 \\
18 & 1.604 & 78 & 0.237 & 0.825 & 0.1613 \\
19 & 1.678 & 78 & 0.250 & 0.811 & 0.1646 \\
20 & 1.752 & 84 & 0.258 & 0.795 & 0.1633 \\
\hline \hline
\end{tabular}

Table 2. ATHENA angles, reflectivity and areas computed assuming the baseline coating.

\subsection{Review of baseline coating design}

We perform an independent computation of the on-axis effective area based on the mirror design described above and the coating baseline in order to review the mirror performance. As mentioned before, the coating recipe adopted as baseline for ATHENA is a bilayer, $8 \mathrm{~nm}$ of $\mathrm{B}_{4} \mathrm{C}$ layer on top of a $10 \mathrm{~nm}$ Ir layer. For this baseline geometry, the same coating is adopted for all mirror modules at all radii.

The on-axis effective area derived for the present geometry and coating baseline is illustrated in figure 1 for a realistic surface roughness of $0.45 \mathrm{~nm}$. The contribution of each mirror module ring to the on-axis effective area and reflectivity curves for the mid angle of each mirror module ring are presented in figure 2 .

Experimental results reported previously ${ }^{4,6}$ suggests that surface roughness could be as good as $0.3 \mathrm{~nm}$ for super polished silicon plates, around $0.60 \mathrm{~nm}$ for standard coated SPO before cleaning and stacking, and it could possible reach higher values after stacking of SPO plates into mirror modules. ${ }^{8}$ In figure 3 we demonstrate the effect of surface roughness in the on-axis effective area. We use a roughness of $0.3 \mathrm{~nm}$ as reference and compute the ratios for areas computed assuming other values of roughness. The effect of roughness on the on-axis effective area increases with energy.

The theoretical reflectivity curves presented were generated using the IMD software. ${ }^{16}$

\section{COATING OPTIMISATION AND ALTERNATIVE MATERIALS}

The main goal of coating design optimisation is to increase the telescope's effective area at the energy range around $6 \mathrm{keV}$ relevant for ATHENA science cases. We aim at improving the telescope throughput at energies beyond $5 \mathrm{keV}$ without compromising the well reflecting low energy range. A coating recipe was optimised for each of the mirror module rings results in a total of 20 recipes.

The original baseline $\mathrm{B}_{4} \mathrm{C}$ layer boosts the low energy reflections while the $\mathrm{Ir}$ layer is responsible for the reflection of higher energies. The idea is to optimise the bilayer baseline and introduce extra layers underneath the bilayer to enhance reflection around $6 \mathrm{keV}$. We would like to avoid introducing a complex layer structure as that would result in undesired features on the effective area curves for such a narrow energy range therefor 


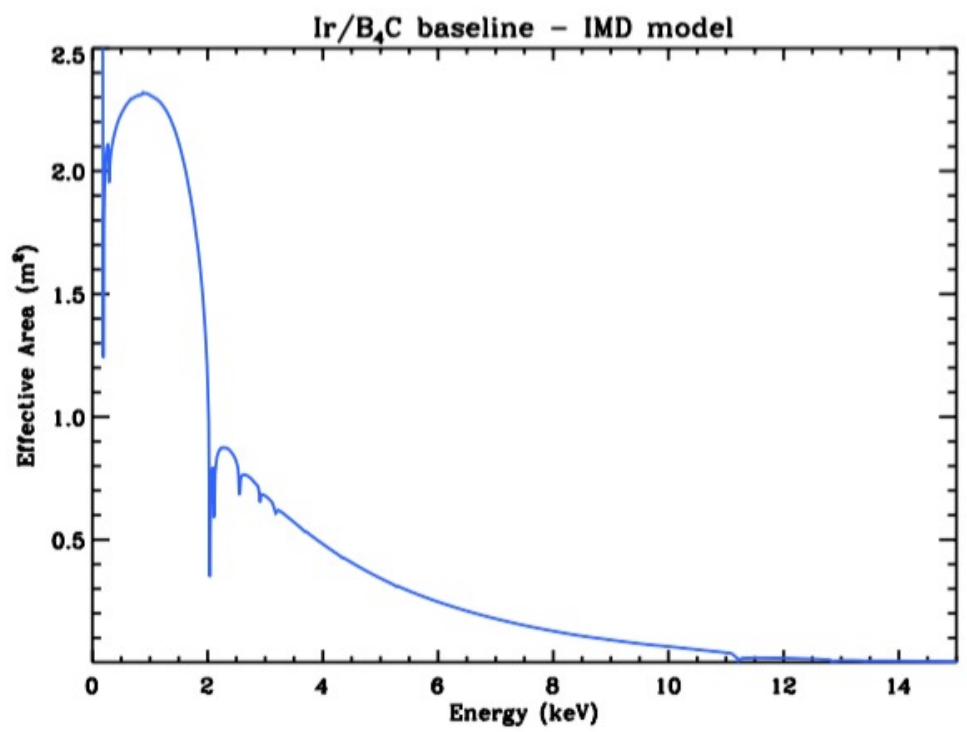

Figure 1. ATHENA effective area as a function of energy. The effective area is computed considering the baseline coating and a surface roughness of $0.45 \mathrm{~nm}$.
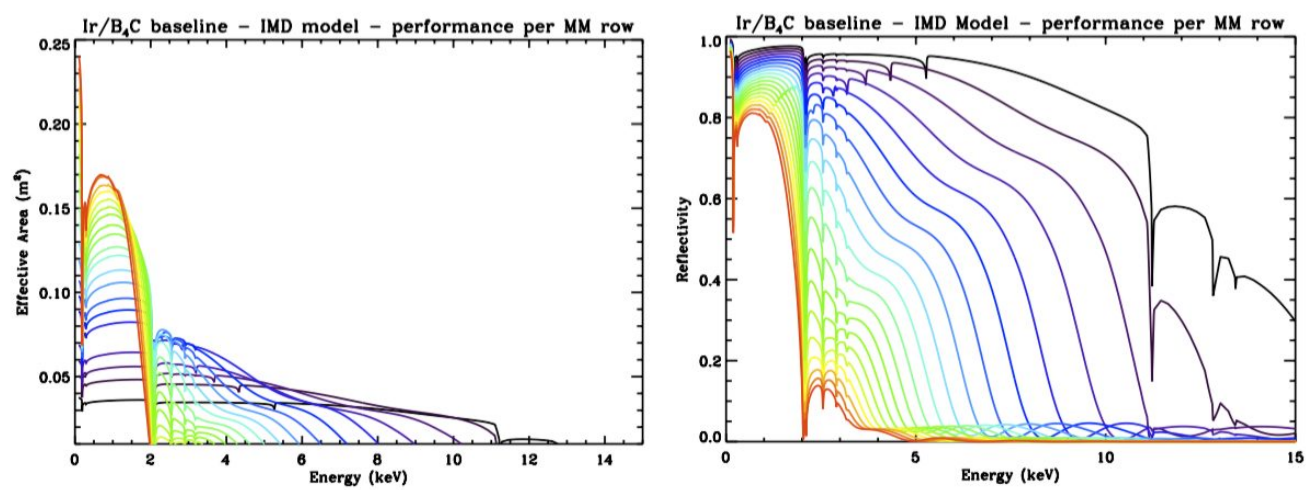

Figure 2. Left: Contribution of each mirror module ring to the on-axis effective area. Right: Reflectivity curve computed for of each mirror module ring. Computations made assuming the baseline coating and a surface roughness of $0.45 \mathrm{~nm}$.
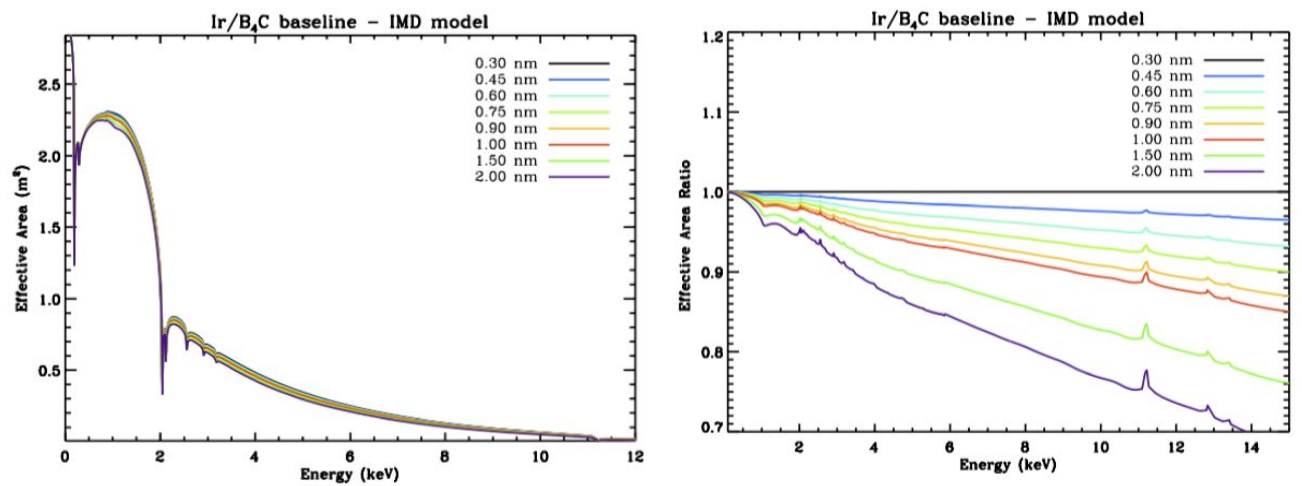

Figure 3. Left: ATHENA effective areas computed considering the baseline coating and different surface roughness. Right: Comparison between the on-axis effective areas for different roughness values. The solid reference line refers to a $0.3 \mathrm{~nm}$ roughness. 

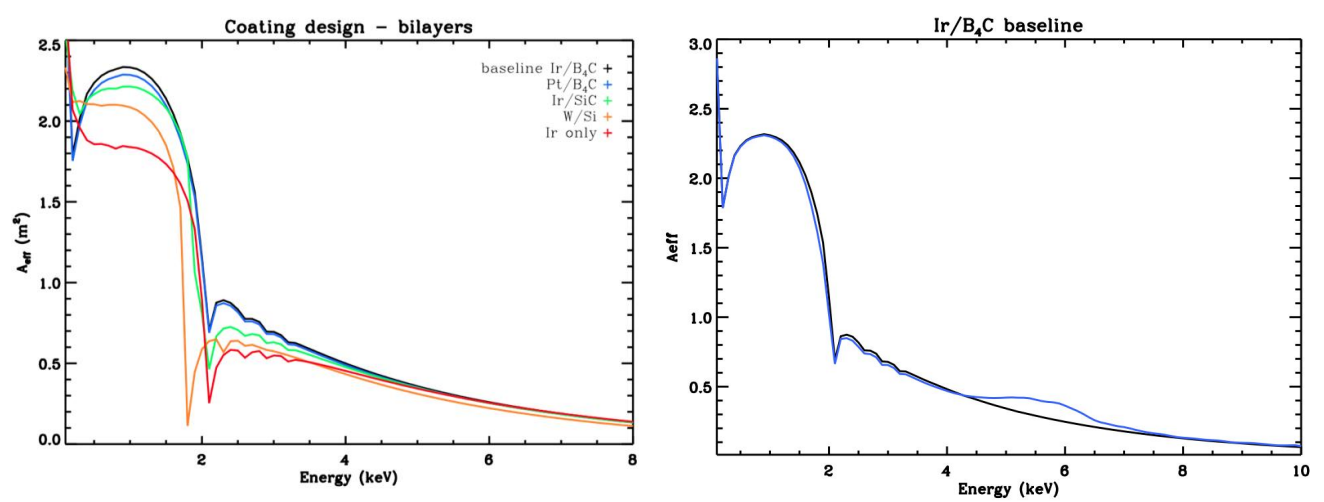

Figure 4. Left: Performance of different materials optimised as bilayer coating and compared to the baseline coating performance. Right: Performance based on the $\mathrm{Ir} / \mathrm{B}_{4} \mathrm{C}$ bilayer baseline coating (black) and optimised linear graded coating recipe (blue).

simple solutions with as few layers as possible are preferred and linear graded multilayers varying between 2 and 50 bilayers were allowed in the calculations.

The starting point is to obtain a solution that maximises the integrated on-axis effective area between 0.1 and $10 \mathrm{keV}$. A figure of merit is defined so that the integrated effective area is multiplied by a Gaussian function with peak at $5 \mathrm{keV}$. In this way, solutions with smooth transition between $5 \mathrm{keV}$ and $8 \mathrm{keV}$ are favoured over solutions maximising narrow ranges at higher energies. A Markov chain Monte Carlo (MCMC) routine was created to search for the maximum of the figure of merit defined as:

$$
\text { F.O.M }=\int_{0.1}^{10} A_{e f f}(E) \cdot a e^{-\frac{(E-b)^{2}}{2 c^{2}}} d E
$$

In equation $3, A_{\text {eff }}$ represents the on-axis effective area, $E$ is the energy, and the parameters of the Gaussian function are $\mathrm{a}=1.0, \mathrm{~b}=5.0 \mathrm{keV}$ and $\mathrm{c}=2.0 \mathrm{keV}$, and the integration is computed from 0.1 to $10 \mathrm{keV}$.

Despite the extensive computation, the results returning from our algorithm still needed refinement. That is due to the degenerated nature of the parameters involving in the coating design. The very best coating design was obtained by "fine tuning" the parameters based on experimental considerations and a priori knowledge of material performance through previous designs. The optimised coating parameters are listed in table 4 . The four innermost rings consist of a single optimised bilayer while the other rings benefit from a simple linear graded multilayer coating (max 15 bilayers).

The best result so far is $47 \%$ improvement for the on-axis effective area at $6 \mathrm{keV}$. The computed on-axis effective areas for both the $\mathrm{Ir} / \mathrm{B}_{4} \mathrm{C}$ baseline and the optimised multilayer coatings are listed in table 3 for a few energies. A surface roughness of $0.45 \mathrm{~nm}$ is assumed. The on-axis effective area curve for the baseline and optimised recipes are shown in figure 4 (right).

Other than optimising the present coating baseline by introducing a linear graded multilayer, we have also investigated the performance of other material combinations suitable for X-ray optics within the desired energy range. We performed optimisation of the bilayer coatings for $\mathrm{Pt} / \mathrm{B}_{4} \mathrm{C}, \mathrm{Ir} / \mathrm{SiC}, \mathrm{W} / \mathrm{Si}$ and for a single layer of Ir. In figure 4 (left) we can observe that none of the listed material combinations perform as good as the $\operatorname{Ir} / \mathrm{B}_{4} \mathrm{C}$ baseline coating.

\subsection{Effects of deposition on the coating performance}

We evaluate the possible effects of coating deposition on the telescope performance by considering cases where the deposition process do not match the desired coating recipe.

For the baseline bilayer coating, a $20 \%$ thicker coating layer does not affect the performance of the telescope while a $20 \%$ thinner coating will reduce the performance marginally and not in any significant way. The 


\begin{tabular}{cccccc}
\hline \hline On-axis effective area & $1 \mathrm{keV}$ & $4 \mathrm{keV}$ & $5 \mathrm{keV}$ & $6 \mathrm{keV}$ & $7 \mathrm{keV}$ \\
\hline \hline Baseline coating & 2.309 & 0.482 & 0.343 & 0.247 & 0.178 \\
Optmised coating & 2.300 & 0.469 & 0.421 & 0.363 & 0.209 \\
Improvement & $-0.4 \%$ & $-2.8 \%$ & $+23 \%$ & $+47 \%$ & $+17 \%$ \\
\hline
\end{tabular}

Table 3. Comparison between baseline and optimised coating performances. On-axis effective areas computed assuming surface roughness of $0.45 \mathrm{~nm}$ for both coating recipes.

\begin{tabular}{ccccccc}
\hline \hline Row & $\mathrm{N}$ & $\begin{array}{c}\text { top } \mathrm{B}_{4} \mathrm{C} \\
(\mathrm{nm})\end{array}$ & $\begin{array}{c}\text { top Ir } \\
(\mathrm{nm})\end{array}$ & $\begin{array}{c}\mathrm{d}_{\min } \\
(\mathrm{nm})\end{array}$ & $\begin{array}{c}\mathrm{d}_{\max } \\
(\mathrm{nm})\end{array}$ & $\Gamma$ \\
\hline 1 & 0 & 8.0 & 10.0 & - & - & - \\
2 & 0 & 8.0 & 10.0 & - & - & - \\
3 & 0 & 8.0 & 10.0 & - & - & - \\
4 & 0 & 8.0 & 10.0 & - & - & - \\
5 & 2 & 8.0 & 10.0 & 3.0 & 10.5 & 0.4 \\
6 & 10 & 8.0 & 8.0 & 3.0 & 10.0 & 0.4 \\
7 & 10 & 8.0 & 7.5 & 3.0 & 9.5 & 0.4 \\
8 & 15 & 8.0 & 6.0 & 3.0 & 9.5 & 0.4 \\
9 & 15 & 8.0 & 6.0 & 3.0 & 9.0 & 0.4 \\
10 & 15 & 8.0 & 6.0 & 3.0 & 7.5 & 0.4 \\
11 & 15 & 8.0 & 6.0 & 3.0 & 7.5 & 0.4 \\
12 & 15 & 8.0 & 6.0 & 3.0 & 7.0 & 0.4 \\
13 & 15 & 8.0 & 6.0 & 3.0 & 6.0 & 0.4 \\
14 & 15 & 8.0 & 6.0 & 3.0 & 5.5 & 0.4 \\
15 & 15 & 8.0 & 6.0 & 3.0 & 5.5 & 0.4 \\
16 & 15 & 8.0 & 6.0 & 3.0 & 5.0 & 0.4 \\
17 & 15 & 8.0 & 6.0 & 3.0 & 4.5 & 0.4 \\
18 & 15 & 8.0 & 6.0 & 3.0 & 4.5 & 0.4 \\
19 & 15 & 8.0 & 6.0 & 3.0 & 4.5 & 0.4 \\
20 & 15 & 8.0 & 6.0 & 3.0 & 4.5 & 0.4 \\
\hline \hline
\end{tabular}

Table 4. Optimised linear graded multilayer coating recipe. 

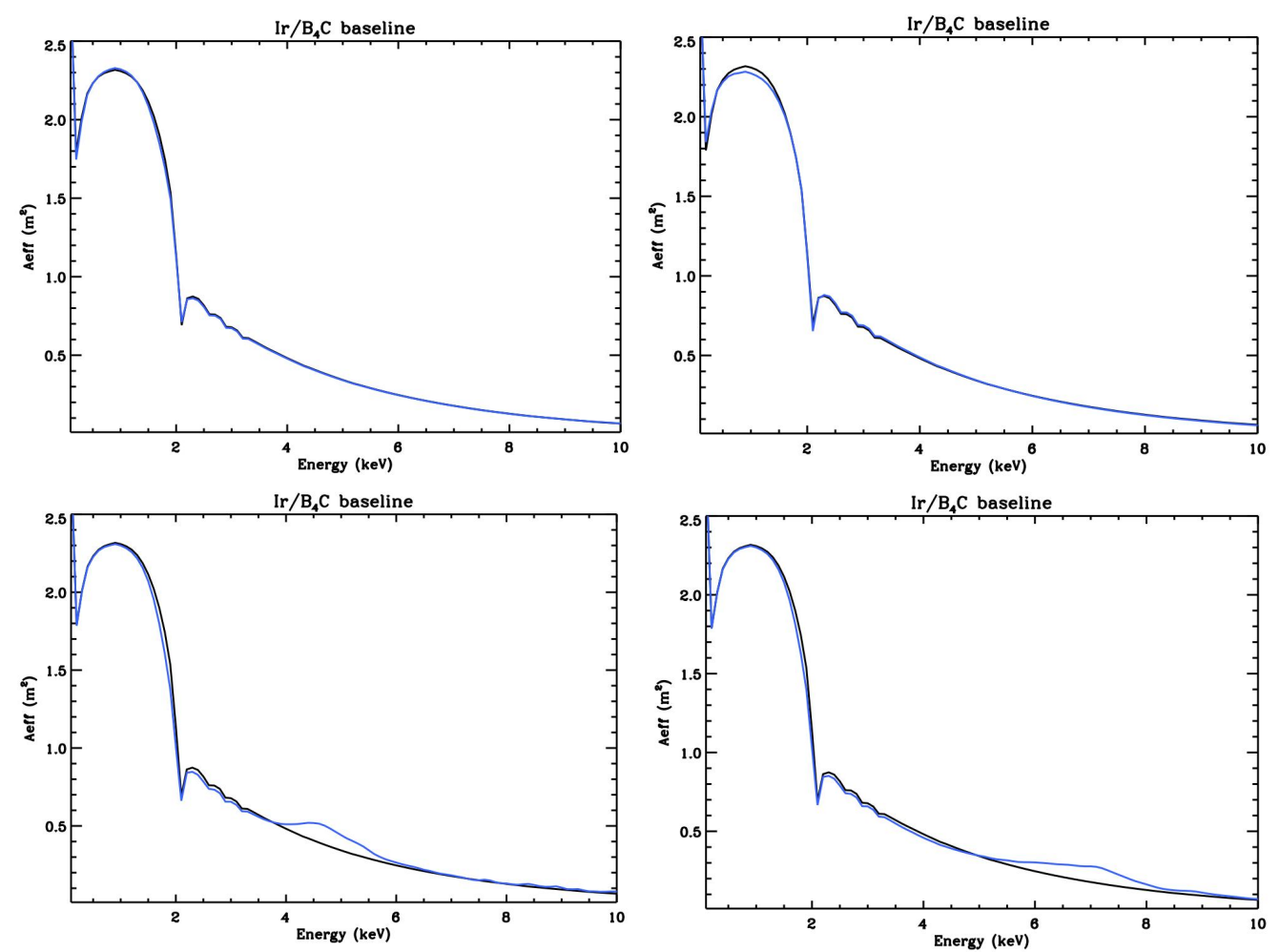

Figure 5. For all plots: In black we have the effective area computed for $\mathrm{Ir} / \mathrm{B}_{4} \mathrm{C}$ coating baseline and in blue computed considering a $20 \%$ mismatch in coating thickness. Top left: Effect of $20 \%$ increase in bilayer coating thickness on the telescope performance. Top rigth: Effect of $20 \%$ reduction in coating thickness on the telescope performance. Bottom left: Effect of $20 \%$ increase in the multilayer coating thickness on the telescope performance. Bottom right: Effect of 20 $\%$ reduction in the multilayer coating thickness on the telescope performance.

optimised linear graded coating is more sensitive to variations in coating thickness, a $20 \%$ thicker of thinner coating structure will shift the effective area curve affecting the expected performance of the telescope. The effect of layer thickness variation is presented in figure 5 .

At the present time we do not expect that deposited bilayer coatings differ from the desired coating design. Coatings have been produced to match the desired coating recipe with less that $5 \%$ discrepancies.

\section{COATING DEVELOPMENT AND PERFORMANCE}

To test stability and performance of the baseline $\mathrm{Ir} / \mathrm{B}_{4} \mathrm{C}$ bilayer coating we produced several test samples with the coating of interest. The deposition was performed using the DC magnetron sputtering facility at DTU Space. $\mathrm{X}$-ray reflectometry (XRR) was used to characterise the samples.

\subsection{Possible effects of lift-off on coating performance}

To lift-off of the photoresist pattern present at the SPO plates and have coated plates ready for stacking it is necessary to make use of solvent materials such as acetone or dimethyl sulfoxide (DMSO).

After coating, lift-off and cleaning are the final steps before SPO stacking. Details on photoresist development, deposition on SPOs and stacking of coated SPOs are reported in. ${ }^{7,8,14}$ The lift-off process removes the photoresist pattern, leaving behind alternating coated, X-ray reflecting areas and substrate bonding areas.

To evaluate the effect of typical solvents on the deposited coatings, test samples coated with $\mathrm{Ir} / \mathrm{B}_{4} \mathrm{C}$ where submersed in DMSO and acetone baths mimicking the real lift-off process of coated SPOs. The test samples were characterised with XRR at $8 \mathrm{keV}$ before and after chemical exposure. The wet chemistry experiments 

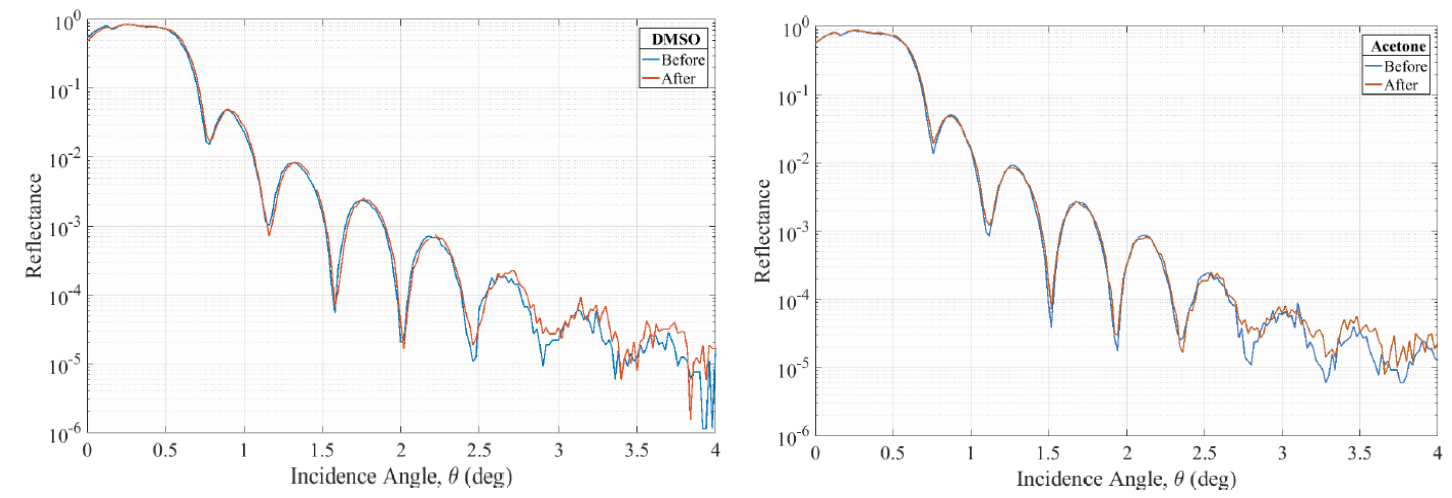

Figure 6. XRR measurements performed at $8 \mathrm{keV}$ of sample Si6383 (left) and sample 6397 (rigth), before and after the DMSO and Acetone exposures.

\begin{tabular}{ccccc} 
& Si6383 & Si6383 & Si6397 & Si6397 \\
\hline \hline material & $\begin{array}{c}\text { best-fit thickness } \\
\text { pre-DMSO }\end{array}$ & $\begin{array}{c}\text { best-fit thickness } \\
\text { post-DMSO }\end{array}$ & $\begin{array}{c}\text { best-fit thickness } \\
\text { pre-Acetone }\end{array}$ & $\begin{array}{c}\text { best-fit thickness } \\
\text { post-Acetone }\end{array}$ \\
\hline Ir & $9.2 \mathrm{~nm}$ & $9.1 \mathrm{~nm}$ & $9.6 \mathrm{~nm}$ & $9.5 \mathrm{~nm}$ \\
\hline \hline
\end{tabular}

Table 5. Best fitting Ir thickness for sample Si6383 (DMSO) and sample 6397 (Acetone), before and after the DMSO and Acetone exposures.

were conducted inside a class 10-100 cleanroom located at DTU Danchip, part of the Technical University of Denmark.

The XRR measurements performed at $8 \mathrm{keV}$ before and after chemical exposure are shown in figure 6 . The best fit Ir thickness obtained by modelling the data using the software IMD $^{16}$ are listed in table 5 .

We do not observe change in the coating performance at $8 \mathrm{keV}$ after exposure to DMSO or acetone. That indicates robustness of the Ir layer as it's performance seems unaffected at $8 \mathrm{keV}$. This data, in the other hand, does not allow for proper characterisation of the top $\mathrm{B}_{4} \mathrm{C}$ layer, therefore inclusion of low energy data in needed to evaluate the performance of the top $\mathrm{B}_{4} \mathrm{C}$ layer along with $\mathrm{AFM}$ characterisation for an insight on what solvent chemical can do to the surface of the coating.

\subsection{Thermal stability}

Thermal stability of mirror coating is important for stable performance of the telescope before, during and after launch. In this study, we investigated the effect of annealing on $\mathrm{Ir} / \mathrm{B}_{4} \mathrm{C}$ bilayer coatings. Annealing is known to increase the strength of bonding ${ }^{17}$ and might be introduced as of the production of SPO mirror modules to increase the shock stability of SPO stacks.

Silicon witness samples were coated with the $\mathrm{Ir} / \mathrm{B}_{4} \mathrm{C}$ baseline at DTU Space to test thermal stability. XRR measurements were performed using a $\mathrm{Cu} \mathrm{K} \mathrm{K}_{\alpha} 8 \mathrm{keV}$ source at the X-ray facility at DTU Space before and after annealing while measurements to determine the reflectivity as function of the photon energy were performed with synchrotron radiation (SR) at the four-crystal monochromator beamline in the laboratory of PTB at BESSY II in Berlin. ${ }^{18}$

Under annealing, the samples undergo thermal heating up to $200{ }^{\circ} \mathrm{C}$ for 50 hours plus 2 hours of pre-heating. For this pilot study we performed tests at $50{ }^{\circ} \mathrm{C}, 100{ }^{\circ} \mathrm{C}$ and $200{ }^{\circ} \mathrm{C}$.

The purpose of thermal tests was to verify whether the annealing procedure affects the coating performance. For all XRR measurements at $8 \mathrm{keV}$ performed before and after thermal exposure we do not observe any significant effect on the coating reflectivity. Comparing the energy scans for reference unheated sample and samples heated to $50{ }^{\circ} \mathrm{C}, 100{ }^{\circ} \mathrm{C}$ and $200{ }^{\circ} \mathrm{C}$ we see that the shape of the reflectivity curve of the sample heated to $200{ }^{\circ} \mathrm{C}$ has changed indicating that the top layer and probably the interface between the two layers has been 

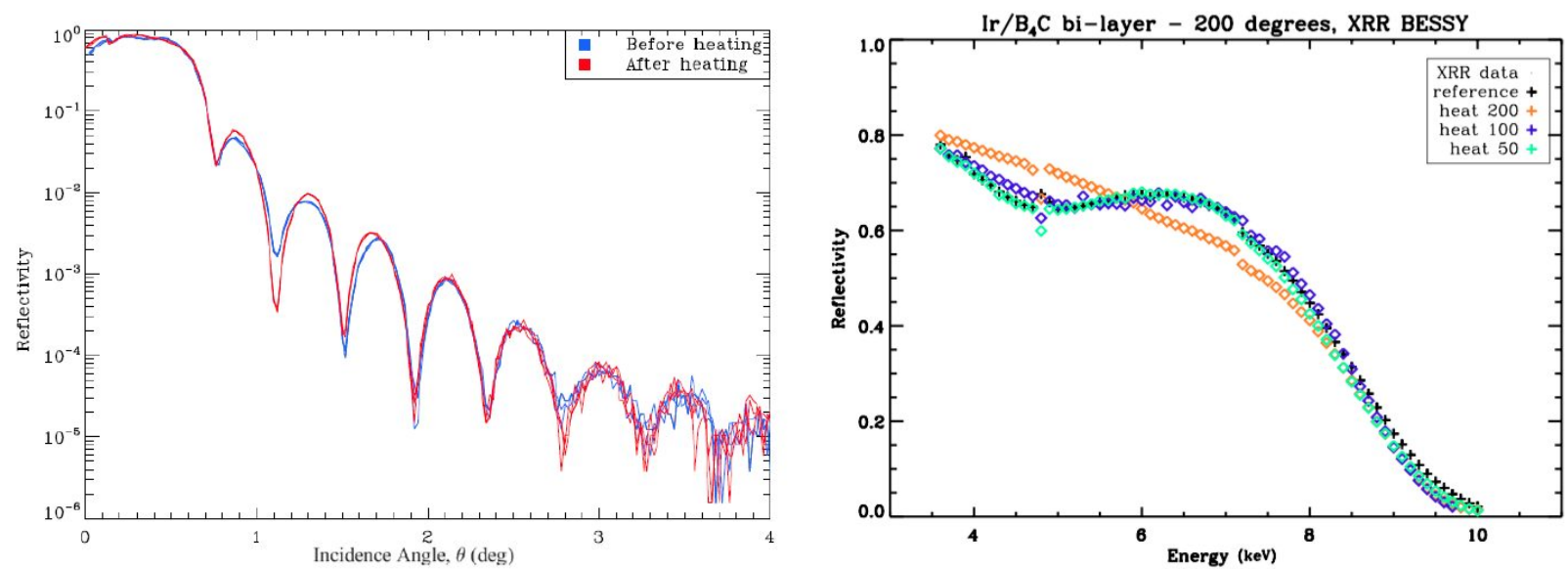

Figure 7. XRR data at $8 \mathrm{keV}$ (left) taken before and after the sample was heated to $200{ }^{\circ} \mathrm{C}$ and energy scan (right) for reference unheated sample and samples heated to $50{ }^{\circ} \mathrm{C}, 100{ }^{\circ} \mathrm{C}$ and $200{ }^{\circ} \mathrm{C}$.

affected. The fact that no variation is seen in the $8 \mathrm{keV}$ data indicates that the Ir layer is robust over the annealing procedure. The XRR data at $8 \mathrm{keV}$ and energy scan are shown in figure 7 . The grazing incident angle for energy scans is $0.6^{\circ}$ for all measurements.

\section{SUMMARY}

We have reviewed the ATHENA baseline geometry and coating by performing independent calculations of the telescope effective area and simulation of mirror performance.

Coating design optimisation can lead to an improvement on the telescope's throughput in the energy range above $5 \mathrm{keV}$. The best improvement achieved is $47 \%$ increase of on-axis effective area at $6 \mathrm{keV}$. This is achieved by introducing a fairly simple $\mathrm{Ir} / \mathrm{B}_{4} \mathrm{C}$ linear graded multilayer coating underneath an optimised bilayer coating.

Effects of surface roughness and variation of coating layer thickness due to deposition calibration are explored. We find that the baseline coating is robust over coating variations.

Present preliminary results on effect of lift-off and annealing on $\mathrm{Ir} / \mathrm{B}_{4} \mathrm{C}$ bilayer coatings. We do not observe significant effect on the performance of the coatings at $8 \mathrm{keV}$ after exposure to DMSO or acetone, that indicates that the Ir layer performance is unaffected but it does not mean that the bilayer coating is intact, as $8 \mathrm{keV} \mathrm{XRR}$ data does not allow for proper characterisation of the top $\mathrm{B}_{4} \mathrm{C}$ layer. The effect of annealing at $200{ }^{\circ} \mathrm{C}$ is also undetected at $8 \mathrm{keV}$ while energy scans between $3.4 \mathrm{keV}$ and $10 \mathrm{keV}$ show change in the coating reflectivity. Annealing is known to strengthen the stacking bonding but is not a indispensable step for SPO stacking. Testing the effect of annealing is relevant to understand the limits of coating performance and extreme conditions. In this study we observe no significant variations in coating reflectivity for the energy range studied after annealing for 50 hours at $50^{\circ}$ and $100{ }^{\circ} \mathrm{C}$.

\section{ACKNOWLEDGMENTS}

This activity is funded by the European Space Agency under contract 4000102248/12/NL/PM.

\section{REFERENCES}

[1] Nandra, K., Barret, D., Barcons, X., and et al., "The hot and energetic universe: A white paper presenting the science theme motivating the athena+ mission," astro-ph.HE arXiv:1306.2307 (2013).

[2] Jakobsen, A. C., Ferreira, D. D. M., Christensen, F. E., Shortt, B., Collon, M., and Ackermann, M. D., "Preliminary coating design and coating developments for ATHENA," Proceedings of SPIE 8147 (2011). 
[3] Ferreira, D. D. M., Christensen, F. E., Jakobsen, A. C., Westergaard, N. J. S., and Shortt, B., "ATHENA coating optimization," Proceedings of SPIE 8443 (2012).

[4] Ferreira, D. D. M., Jakobsen, A. C., Christensen, F. E., and et al., "Development and characterization of coatings on Silicon Pore Optics substrates for the ATHENA mission," Proceedings of SPIE 8443 (2012).

[5] Ferreira, D. D. M., Christensen, F. E., Jakobsen, A. C., and et al., "Coating optimization for the ATHENA+ mission," Proceedings of SPIE $\mathbf{8 8 6 1}$ (2013).

[6] Della Monica Ferreira, D., Jakobsen, A., Massahi, S., Christensen, F., Shortt, B., Garnaes, J., Torras-Rosell, A., Krumrey, M., Cibik, L., and Marggraf, S., "X-ray mirror development and testing for the ATHENA mission," Proceedings of SPIE 9905 (2016).

[7] Massahi, S., Girou, D., Ferreira, D. D. M., and et al., "Investigation of Photolithography Process on SPOs for the ATHENA Mission," Proceedings of SPIE 9603 (2015).

[8] Massahi, S., Della Monica Ferreira, D., Christensen, F., Shortt, B., Girou, D., Collon, M., Landgraf, B., Barriere, N., Krumrey, M., Cibik, L., and Schreiber, S., "Development and production of a multilayer-coated x-ray reflecting stack for the athena mission," Proceedings of SPIE 9905 (2016).

[9] Nandra, K., Barret, D., Barcons, X., and et al., "The Hot and Energetic Universe: A White Paper presenting the science theme motivating the Athena+ mission," arXiv 1306.2307v1 (2013).

[10] ESA, "ATHENA CDF Study Report: CDF-150(A)," tech. rep., European Space Agency (2014).

[11] Oosterbroek, T. and ESA, "ATHENA telescope reference design and effective area estimates," tech. rep., European Space Agency (2014).

[12] Willingale, R., Pareschi, G., Christensen, F., and den Herder, J., "The hot and energetic universe: The optical design of the athena+ mirror," astro-ph.IM arXiv:1307.1709 (2013).

[13] Bavdaz, M., Peacock, A. J., Tomaselli, E., Beijersbergen, M. W., Collon, M., and et al., "Progress at ESA on High Energy Optics technologies," Proceedings of SPIE 5168 (2004).

[14] Collon, M. J., Vacanti, G., Guenther, R., and et al., "Silicon pore optics for the athena telescope," Proceedings of SPIE 9905 (2016).

[15] Windt, D., "IMD - Software for modeling the optical properties of multilayer films," Computers in Physics 12(4), 360-370 (1998).

[16] Windt, D. L., "IMD - Software for modeling the optical properties of multilayer films," Computers in Physics 12, 360-370 (Jan. 1998).

[17] Tong, Q.-Y. and Gsele, U., "A model of low-temperature wafer bonding and its applications," J. Electrochem. Soc 143 (1996).

[18] Krumrey, M. and Ulm, G., "High accuracy detector calibration at the PTB four-crystal monochromator beamline," Nucl. Instr. and Meth. A 1175 - 1178, 467 - 468 (2001). 